\title{
The burrow of Dasypus hybridus (Cingulata: Dasypodidae)
}

\author{
Enrique M. GONZÁLEZ, Alvaro SOUTULLO and Carlos A. ALTUNA
}

González E. M., Soutullo A. and Altuna C. A. 2001. The burrow of Dasypus hybridus (Cingulata: Dasypodidae). Acta Theriologica 46: 53-59.

Dasypus hybridus (Desmarest, 1804) inhabits open fields in southern South America. Burrows of $D$. hybridus were cylindrical with a conical end. They had an entrance and a single tunnel without branches. Three locations of the burrows in the terrain were detected: in banks of dried waterways, near rocks, and in open field. The orientation of 29 burrow mouths was not random and, although they did not point to any cardinal point, in particular there was a strong tendency to avoid the south quadrant. In a sample area of $90 \times 140 \mathrm{~m}$, burrow mouths were arranged in a random spatial pattern with a density of 25.4 burrows per ha. Great variation in burrow length was found $(118.8 \pm 105.69 \mathrm{~cm}, \mathrm{CV}=89.0 \%)$. Tunnels may be used as refuges and/or for thermoregulation. The orientation of burrow mouths can also be related to thermoregulation as tunnels are covered from dominant winds, and, for many hours every day, the temperature at the mouths can be influenced by insolation. The possible existence of shelter-burrows and resting-burrows is discussed.

Museo Nacional de Historia Natural, CC 399, 11.000 Montevideo, Uruguay, e-mail: vidasilvestre@interamerica.com.uy (EMG); VIDA SILVESTRE, Sociedad Uruguaya para la Conservación de la Naturaleza, Colonia 1884/903, 11.200 Montevideo, Uruguay, e-mail: sutu@adinet.com.uy (AS); Sección Etología, Facultad de Ciencias, Iguá 4225, 11.400 Montevideo, Uruguay, e-mail: caltuna@fcien.edu.uy (CAA)

Key words: Dasypus hybridus, armadillo, burrow, Uruguay

\section{Introduction}

Burrow building is characteristic of all species of armadillos, with the only exception of the genus Tolypeutes (Redford and Eisenberg 1992), that use structures of other species. These structures are important for the defensive strategies of the species, as armadillos scurry back to them and hide there when threatened (Cabrera and Yepes 1940), as reported for other burrowing mammals (Reichman and Smith 1990). However, there is no information about other uses of the burrows. Many aspects of the behaviour of armadillos inside the burrows are unknown. The external features of burrows and their location in armadillo habitat are variable, and it is possible to recognise some species through the epigeous characteristics of burrows (González and Ríos 1980). The hipogeous structures, however, are barely known.

The burrow characteristics of 8 species of armadillos have been described: Chaetophractus vellerosus, C. villosus and Zaedyus pichiy (Crespo 1944), Dasypus novemcinctus (Taber 1945, Clark 1951), Cabassous unicinctus, C. tatouay, Euphractus 
sexcinctus and Priodontes maximus (Carter 1983, Carter and Encarnaçao 1983). Four species of armadillos have been recorded in Uruguay: Dasypus hybridus, D. novemcinctus, E. sexcinctus and Cabassous tatouay (Achaval 1989). Among them, $D$. hybridus is the only species whose burrows have not yet been described.

The geographic range of $D$. hybridus ("mulita") includes southern Paraguay, northern and central Argentina, probably southern Bolivia, Uruguay and southern Brazil (Wetzel and Mondolfi 1979, Wetzel 1982). This armadillo inhabits open fields (Silva 1984). The conservation status of the species within Uruguay varies among regions. While it has been extirpated or is very threatened in some areas, it is abundant in others, such as our study area. The total length reported for specimens of this species ranges between 39.7 and $49.8 \mathrm{~cm}$, and the weight between 1.09 and $2.04 \mathrm{~kg}$ (Redford and Eisenberg 1992). The aim of this research was to describe the structure, location and spatial pattern of the burrows of D. hybridus.

\section{Material and methods}

The field work was carried out between February and May of 1997 in an area near the confluence of two waterways: Arroyo Illescas and Cañada Victoria in the Departamento de Florida, Uruguay $\left(33^{\circ} 20^{\prime} \mathrm{S}, 55^{\circ} 20^{\prime} \mathrm{W}\right)$. The topography of the area is characterised by small hills (altitude ca $200 \mathrm{~m}$ ) crossed by the Arroyo Illescas and tributary waterways. The terrain has very scarce and low vegetation cover (mostly grasslands), and the soil is bare in some places. Rocky outcrops are very common.

A $12-\mathrm{km}$ transect (in an area of ca $400 \mathrm{ha}$ ) was preliminarily sampled to record the number of active burrows, the characteristics of the terrain where the burrows were located, and characteristics of their entrances. Burrows were considered active when the tunnel was not obstructed in the first $30 \mathrm{~cm}$. Twenty burrows were completely excavated. Maximum length, width, and depth of tunnels and chambers were measured with a measuring tape (with accuracy of $1 \mathrm{~cm}$ ) and the galleries were drawn at scale on a graph paper. Data on metric features of tunnels were expressed as mean $\pm \mathrm{SD}$, and coefficient of variability (CV).

The spatial pattern of burrows was studied in a grid of $90 \times 140 \mathrm{~m}$ using the Donnelly modification of the Clark and Evans test (Krebs 1989). All the active burrows within the grid were counted and the position of each burrow mouth was mapped. When burrows had more than one mouth, a point between them was selected to represent the burrow on the map. The cardinal orientation of 29 burrow mouths (ie surface openings) was stated with a compass as N, NE, E, SE, S, SW, W or NW.

\section{Results}

Of 216 active burrows recorded in the preliminary sample, $11(5.1 \%)$ were found in small ravines of seasonally dried streams, $12(5.6 \%)$ against rocks, and the remaining $193(89.3 \%)$ in open field; $120(55.6 \%)$ had dried grasses in the mouth and/or in the first $30 \mathrm{~cm}$ of the tunnel; $174(80.6 \%)$ had a simple entrance, and 42 $(19.4 \%)$ a bifurcated one (ie with 2 mouths). As entrance we considered the access $\operatorname{ramp}(\mathrm{s})$, the mouth(s) and the first part of the underground tunnel, until it turned parallel to the ground surface. The entrance may follow the tunnel direction or not. We defined the entrance and the first $30 \mathrm{~cm}$ of the tunnel as the "atrium". Different kinds of entrances and other features of the burrows are shown in Fig. 1. Several 


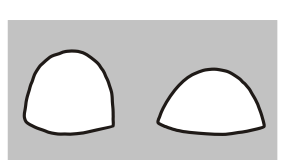

a

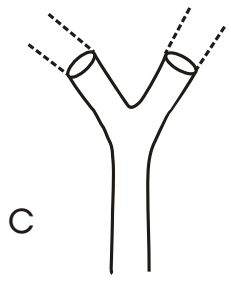

e

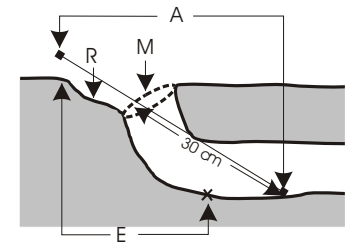

b
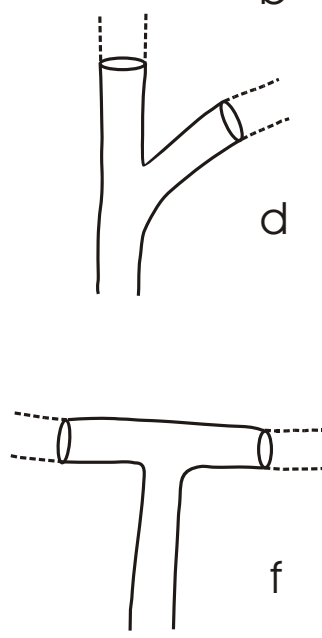

Fig. 1. (a) Cross section of a typical burrow of Dasypus hybridus (two different types of tunnels are represented). (b) Sagital view of a burrow with simple entrance $(\mathrm{R}-$ access ramp, $\mathrm{M}-$ mouth, A - atrium, E - entrance, x - point where the tunnel turns parallel to the ground). Different kinds of bifurcated entrances (continuous lines represent underground structures, dotted lines above ground structures): (c) in "Y",

(d) with an accessory entrance, (e) with "chimney", (f) in "T".
Table 1. Maximum length, width and depth (cm) of the 20 excavated burrows of Dasypus hybridus. "-" - no data, $\bar{x}$ - arithmetic media, $n$ - sample size, SD - standard deviation, $\mathrm{CV}$ - coefficient of variability.

\begin{tabular}{|c|c|c|c|}
\hline & Length & Width & Depth \\
\hline & 80 & 23 & - \\
\hline & 50 & 30 & - \\
\hline & 135 & 12 & 36 \\
\hline & 270 & 13 & 45 \\
\hline & 60 & 15 & 37 \\
\hline & 40 & 13 & - \\
\hline & 70 & 12 & 48 \\
\hline & 90 & 14 & 38 \\
\hline & 62 & - & 36 \\
\hline & 100 & 24 & 43 \\
\hline & 83 & 13 & 33 \\
\hline & 170 & 18 & 54 \\
\hline & 40 & 15 & 32 \\
\hline & 100 & 12 & 42 \\
\hline & 96 & 14 & 35 \\
\hline & 50 & 15 & - \\
\hline & 90 & 15 & 45 \\
\hline & 105 & 12 & 60 \\
\hline & 185 & 10 & - \\
\hline & 500 & 10 & 67 \\
\hline $\bar{x}$ & 118.8 & 15.3 & 43.4 \\
\hline$n$ & 20 & 19 & 15 \\
\hline SD & 105.69 & 5.15 & 10.22 \\
\hline CV & 89.0 & 33.8 & 23.5 \\
\hline
\end{tabular}

individuals of the lizard Pantodactylus schreibersii were found in the dried grasses hoarded in the tunnels close to burrow mouths.

The 20 burrows we excavated were approximately cylindrical with a conical end. They consisted of an entrance and a single tunnel without branches. In 6 burrows the tunnels got wider, forming a chamber (maximum width: $25.6 \pm 6.19 \mathrm{~cm}$, $\mathrm{CV}=24.2 \%, n=5$; maximum depth: $35.2 \pm 8.49 \mathrm{~cm}, \mathrm{CV}=24.1 \%, n=6$ ), usually near the mouth. Table 1 shows maximum length, width and depth of each excavated burrow. Hoarded dried grasses were found in chambers and tunnels of some burrows. The main features of 5 burrows are shown in Fig. 2.

Thirty-two burrows were recorded in the grid used to study spatial pattern. The Clark and Evans index of aggregation calculated for the grid was 1.0544, which was 


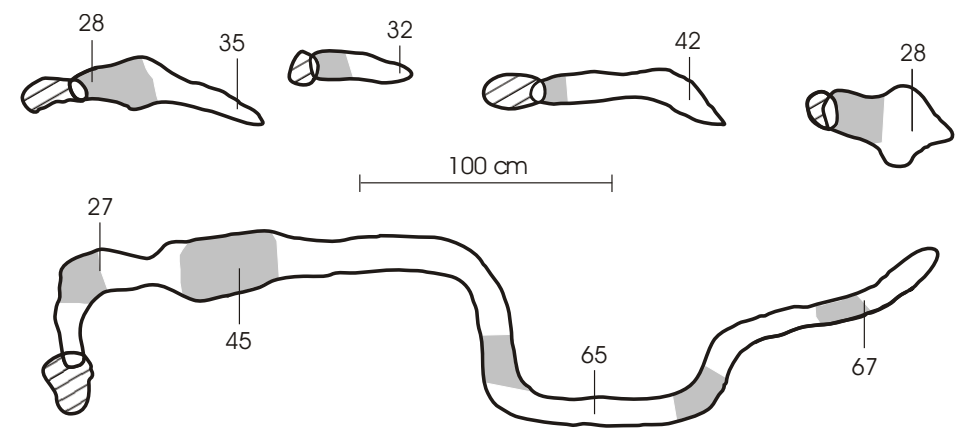

Fig. 2. Aerial view of five burrows of Dasypus hybridus. Numbers show the depth $(\mathrm{cm})$ of the galleries at that point. Dotted zones represent hoarded grasses and striped ones access ramps.

not significantly different from randomness $(\mathrm{z}=0.5359, p>0.05)$. So burrows were spaced at random. Fig. 3 shows the position of the mouths within the grid. Burrows density in that area was 25.4 burrows/ha.

The orientation of the burrow mouths was not random (Fig. 4). Although they pointed to every cardinal direction, there was a tendency to avoid the south quadrant [Rayleigh's test (Lehner 1996): $\mathrm{z}=3.6, n=29, p<0.05$ ].

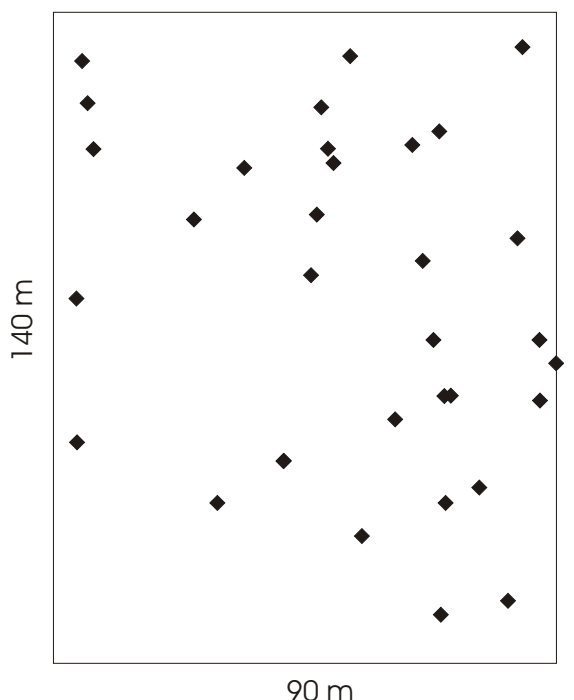

Fig. 3. Random spatial pattern of 32 burrows of Dasypus hybridus in a grid of $90 \times 140 \mathrm{~m}$ in Departamento de Florida, Uruguay.

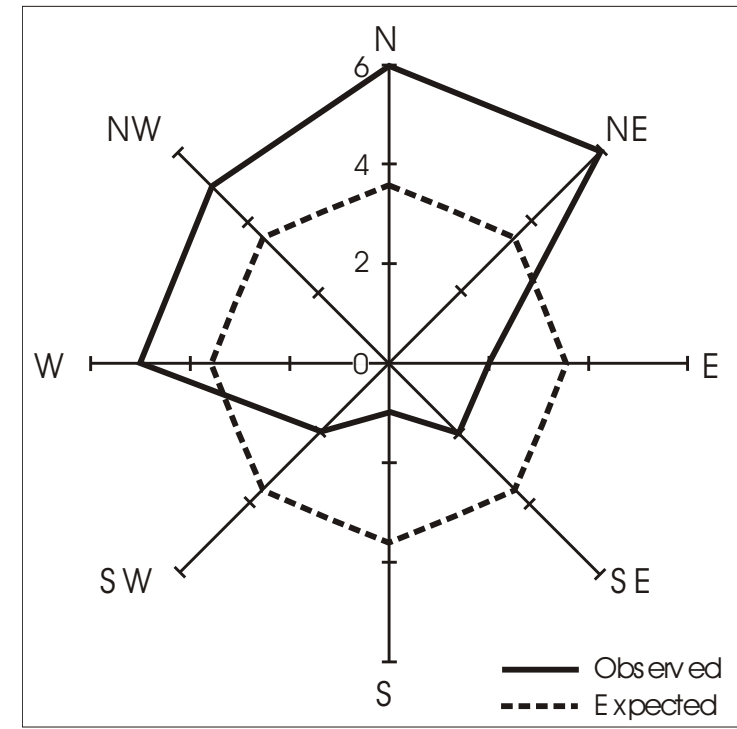

Fig. 4. Frequency polygon of the cardinal orientation of 29 burrow mouths. There was a significant tendency to avoid the south quadrant. 


\section{Discussion}

Valuable information on a species's biology may arise from the analysis of the structure and spatial pattern of its burrows (Hickman 1990, Reichman and Smith 1990). Simple burrows, such as those of D. hybridus, consisting of little more than an entrance, a short tunnel and perhaps a chamber, can provide basic protection (Reichman and Smith 1990). As mentioned before, "mulitas" scurry back to their burrows and hide there when they are threatened. If D. hybridus spends as many hours sleeping each day as D. novemcinctus does (Yaksh et al. 1967, Prudom and Klemm 1973, Mc Donough and Loughry 1997), then the main functions of $D$. hybridus burrows may be to provide shelter from predators and act as resting sites.

Our results showed great variation in burrow length. This may suggest that different burrows have different uses. Most of the excavated tunnels measured near $1 \mathrm{~m}$ in length, and only a few more than $1.5 \mathrm{~m}$. Hiding from predators requires better access to burrows than resting does, so $100 \%$ of the burrows are expected to be used, at least, as refuges. However, resting needs may vary seasonally. In summer, resting requirements may be met by any burrow, but in winter the use of longer and deeper burrows may be required as a help for thermoregulation due to the limited thermoregulatory capability (lesser in smaller species) of the armadillos (McNab 1980). Indeed, while we were digging the longest burrow, we noted an inside temperature clearly superior to the one outside (ie environmental temperature). Although digging long galleries may result in an excessive energetic cost, it may be compensated by a direct or indirect return in energetic terms during the cold season (Vleck 1979), and/or prevent overheating in summer. An alternative (probably complementary) hypothesis is that long burrows mainly function as shelters for offspring from predators and/or adverse environmental conditions. If so, then the advantages for an adult in building those energetically costly burrows would be mainly related to fitness, in terms of offspring survival (which probably have even poorer thermoregulatory control), instead of being related to adult thermoregulation.

A strategy implying differential use of burrows has been reported for the rodent "vizcacha" Lagostomus maximus by Branch et al. (1994). L. maximus has principal burrows and satellite burrows, the latter being temporary refuges.

Burrow mouth avoided facing the south quadrant. This observation coincides with those of Crespo (1944) for other Dasypodidae. Orientation is also probably related to thermoregulation. In this way the tunnels are covered from the dominant winds in Uruguay, which come from the south quadrant (Altuna 1991). Besides, for many hours every day, the temperature at the mouths can be influenced by the incidence of solar rays, that in the southern hemisphere reach the surface with an inclination from the north. Mouths oriented to the north should have a higher temperature at the atrium, which could be an explanation for the fact that, during the season we carried out the field work, D. hybridus spent much time there (E. M. González, pers. obs.). Eisenberg (1961) reported D. novemcinctus carrying insulating 
litter into a burrow. This adaptive behaviour supports our ideas on the relations between behaviour and poor thermoregulation in armadillos.

The fact that burrow maximum depth was between 32 and $67 \mathrm{~cm}$ is another element supporting the idea that burrows contribute to thermoregulation. As Reichman and Smith (1990) note, at a depth of ca $30 \mathrm{~cm}$ almost all daily temperature fluctuations disappear. Reichman and Smith (1990) suggest that for armadillos the cost of digging and maintaining a simple, shallow burrow system is probably not high compared to other metabolic costs, or that the benefits are so high that they can afford digging fresh burrows as needed. A major question that then arises is: taking into account the trade-offs between excavation costs and the advantage of having more burrows to escape from predators, how many burrows should every "mulita" dig and how often? Another question is how tolerant should these animals be to the presence of conspecifics, as more burrows may provide more chances for escape from predators, but overlapping home ranges may provoke competition for other limiting resources (Layne and Glover 1977).

Clark (1951) did not find antagonism between individual armadillos ( $D$. novemcinctus) and, with a single exception, all home ranges overlapped in his study area. Burrow spatial patterns, however, are not necessarily determined by factors related to population dynamics or demography, social structure, or biotic interactions. They may be influenced by environmental features that determine the selection of sites for locating burrows.

The discovery of a very long burrow and the great variability in burrows length detected may suggest the existence of a differential system of shelter-burrows and resting-burrows, with the latter possibly playing a major role in thermoregulation during the cold season. If this is the case, the proportion of resting-burrows related to shelter-burrows would be low. More information on the ecology and behaviour of $D$. hybridus is needed in order to confirm this pattern and establish what the different burrow types are used for in these animals.

Acknowledgements: We are grateful to J. Sánchez for allowing us to work on his property. Thanks are due to A. Chiamberlando, C. López, G. Fregueiro, F. Scarabino and A. Saralegui for their help with the field work. We acknowledge M. Lima for his critical reading of the manuscript and A. Luz Porzecanski for her contributions to improve English. The field work was supported by VIDA SILVESTRE, Sociedad Uruguaya para la Conservación de la Naturaleza.

\section{References}

Achaval F. 1989. Lista de especies de Vertebrados del Uruguay. Parte 2: Anfibios, reptiles, aves y mamíferos. Facultad de Humanidades y Ciencias, Montevideo: 1-41.

Altuna C. A. 1991. Microclima de cuevas y comportamientos de homeostasis en una población del grupo Ctenomys pearsoni del Uruguay (Rodentia, Octodontidae). Boletín Sociedad Zoológica del Uruguay, 2da. época, 6: 35-46.

Cabrera A. and Yepes J. 1940. Mamíferos Sud-Americanos (vida, costumbres y descripción). Historia Natural Ediar, Compañía Argentina de Editores, Buenos Aires: 1-270.

Carter T. 1983. The burrows of the giant armadillo, Priodontes maximus (Edentata, Dasypodidae). Saügetierkunde Mittelüngen 31: 47-53. 
Carter T. and Encarnaçao C. 1983. Characteristics and use of burrows by four species of armadillos in Brazil. Journal of Mammalogy 64: 103-108.

Clark W. 1951. Ecological life history of the armadillo in the Eastern Edward's plateau region. American Midland Naturalist 46: 337-358.

Crespo J. 1944. Contribución al conocimiento de la ecología de algunos dasipódidos (Edentata) Argentinos. Revista Argentina de Zoogeografía, Buenos Aires 4: 7-39.

Eisenberg J. 1961. Observations on the nest building behaviour of armadillos. Proceedings of the Zoological Society of London 137: 322-324.

González J. C. and Ríos C. 1980. Refugios epigeos del "tatú" Dasypus n. novemcinctus Linné (Mammalia: Dasypodidae). Resúmenes y Comunicaciones Jornadas de Ciencias Naturales, Montevideo 1: $129-130$.

Hickman G. C. 1990. Adaptiveness of tunnel system in subterranean mammal burrows. [In: Evolution of subterranean mammals at the organismal and molecul levels. E. Nevo and O. A. Reig, eds]. Alan R. Liss, New York: 185-210.

Krebs C. 1989. Ecological methodology. Harper Collins, New York: 1-654.

Layne J. N. and Glover D. 1977. Home range of the armadillo in Florida. Journal of Mammalogy 58: 411-413.

Lehner P. N. 1996. Handbook of ethological methods. 2nd ed. Cambridge University Press, Cambridge: $1-672$.

Mc Donough C. M. and Loughry W. J. 1997. Influences on activity patterns in a population of nine-banded armadillos. Journal of Mammalogy 78: 932-941.

McNab B. K. 1980. Energetics and the limits to a temperate distribution in armadillos. Journal of Mammalogy 61: 606-627.

Prudom A. E. and Klemm W. R. 1973. Electrographic correlates of sleep behavior in a primitive mammal, the armadillo Dasypus novemcinctus. Physiology and Behavior 10: 275-282.

Redford K. H. and Eisenberg J. F. 1992. Mammals of the Neotropics, The Southern Cone. Vol. 2. Chile, Argentina, Uruguay, Paraguay. University of Chicago Press, Chicago: I-IX+1-406.

Reichman O. and Smith S. 1990. Burrows and burrowing behaviour by mammals [In: Current mammalogy. H. Genoways, ed]. Plenum Press, New York: 197-244.

Silva F. 1984. Mamíferos Silvestres. Rio Grande do Sul. Fundaçao Zoobotânica de Rio Grande do Sul Porto Alegre: 1-241.

Taber F. 1945. Contributions on the life history and ecology of the nine-banded armadillo. Journal of Mammalogy 26: 211-226.

Vleck D. 1979. The energy cost of burrowing by the pocket gopher Thomomys bottae. Physiological Zoology 52: 122-136.

Wetzel R. 1982. Systematics, distribution, ecology and conservation of South American edentates. [In: Mammalian biology in South America. Pymatuning Symposia of Ecology. 6. M. Mares and H. Genoways, eds]. Special Publication Series, Pittsburgh Pymatuning Laboratory of Ecology, University of Pittsburgh, Pittsburgh: 345-376.

Wetzel R. M. and Mondolfi E. 1979. The subgenera and species of long-nosed armadillos, genus Dasypus L. [In: Vertebrate ecology in the northern Neotropics. J. F. Eisenberg, ed]. Smithsonian Institution Press, Washington DC: 43-63.

Yaksh T., Peacock L. J. and Darby C. L. 1967. Circadian activity cycles in the nine-banded armadillo. Georgia Journal of Science 25: 101.

Received 12 November 1999, accepted 30 May 2000. 